\title{
Nitrosative Stress in the Rat Retina at the Onset of Streptozotocin-Induced Diabetes
}

\author{
Ernesto Hernández-Ramírez ${ }^{\mathrm{a}}$ Gustavo Sánchez-Chávez ${ }^{\mathrm{a}} \quad$ Luis A. Estrella-Salazara $^{\mathrm{a}}$ \\ Rocío Salceda ${ }^{a}$ \\ aDivisión de Neurociencias, Departamento de Neurodesarrollo y Fisiología, Instituto de Fisiología \\ Celular, Universidad Nacional Autónoma de México, México, D.F. 04510, Ciudad de México, México
}

\section{Key Words}

Diabetic retina $• \mathrm{NADPH}-\mathrm{d} \cdot \mathrm{INOS} \cdot$ Nitric oxide $・$ Nitrotyrosine $\bullet$ CGMP $•$ Müller cells $•$ GFAP

\begin{abstract}
Background/Aims. Nitric oxide is a multifunctional molecule that can modify proteins via nitrosylation; it can also initiate signaling cascades through the activation of soluble guanylate cyclase. Diabetic retinopathy is the leading cause of blindness, but its pathogenesis is unknown. Multiple mechanisms including oxidative-nitrosative stress have been implicated. Our main goal was to find significant changes in nitric oxide (NO) levels and determine their association with nitrosative stress in the rat retina at the onset of diabetes. Methods: Diabetes was induced by a single intraperitoneal administration of streptozotocin. The possible nitric oxide effects on the rat retina were evaluated by the presence of nicotinamide adenine dinucleotide phosphate diaphorase (NADPH-d), a specific marker for NO-producing neurons, detected by histochemistry performed on whole retinas and retina sections. Immunohistochemistry was also performed on retina sections for iNOS, 3-nitrotyrosine (3-NT) and glial fibrillary acidic protein (GFAP). Retinal nitric oxide levels were assessed by measuring total nitrate/nitrite concentrations. Retinal cGMP levels were determined by radioimmunoassay. Western blots for nitrotyrosine (3-NT) and oxidized proteins were performed. Results: In the present study, we found increased activity of NADPH-diaphorase and iNOS immunoreactivity in the rat retina at the onset of diabetes; this increase correlated with a remarkable increase in NO levels as early as 7 days after the onset of diabetes. However, cGMP levels were not modified by diabetes, suggesting that NO did not activate its signaling cascade. Even so, Western blots revealed a progressive increase in nitrated proteins at 7 days after diabetes induction. Likewise, positive nitrotyrosine immunolabeling was observed in the photoreceptor layer, ganglion cell layer, inner nuclear layer and some Müller cell processes in the retinas of diabetic rats. In addition, levels of oxidized proteins were increased in the retina early after diabetes induction; these levels were reduced by the administration of L-NAME. In addition, stress in Müller cells was determined by immunoreactivity to the glial fibrillary acidic protein. Conclusions: Our findings indicated the occurrence of nitrosative stress at the onset of diabetes in the rat retina and emphasized the role of $\mathrm{NO}$ in retinal function and the pathogenesis of retinopathy.
\end{abstract}




\section{Introduction}

Nitric oxide (NO) is produced from L-arginine by the catalytic activity of different isoforms of nitric oxide synthase (NOS), including neuronal (nNOS), endothelial (eNOS) and inducible (iNOS) isoforms $[1,2]$. NO is an important signaling molecule that mediates a variety of essential physiological processes, including neurotransmission, vasodilatation, and host cell defense [2-4]. NOS is ubiquitously distributed in the central nervous system, including the retina [5-10], and it co-localizes with nicotinamide adenine dinucleotide phosphate diaphorase (NADPH-d) [6]. NO was found to act through the stimulation of soluble guanylyl cyclase (sGC), with subsequent formation of cyclic GMP (cGMP), which stimulates protein kinase $\mathrm{G}$ and cGMP-regulated phosphodiesterase activities [11-13]. In addition to its function as a potent vasodilator and messenger in the nervous system, nitric oxide can react with thiol residues within proteins to modifying their activity $[14,15]$. NO also reacts with superoxide-forming peroxynitrite, a radical species capable of oxidizing and nitrating biomolecules [16, 17]; thus, it is involved in the pathogenesis of several diseases, including diabetes [18-21]. In the normal retina, NO has been found either to be produced by or to have effects on every retinal cell type [8, 22]. In addition, high levels of NO and upregulation of iNOS levels have been found in the retinas of long-term experimental diabetic rodents and human patients [23-25]. We previously reported an increase in NO levels in the retina after the early stages of diabetes [26]; thus, the purpose of this study was to determine whether retinal NO signaling was modified in the short term in streptozotocin-induced diabetic rats and if the NO levels were related to nitrosative stress. Our main goal was to find significant changes in such levels at the onset of diabetes and determine whether these changes were associated with nitrosative stress in the retina.

\section{Materials and Methods}

\section{Experimental Animals}

Adult Long-Evans rats (170-200 g) were housed under standard laboratory conditions $\left(21 \pm 1^{\circ} \mathrm{C}, 12 \mathrm{~h}\right.$ light-dark cycle beginning at 7:00 a.m.) and allowed free access to food and water. Diabetes was induced by a single intraperitoneal (i.p.) administration of streptozotocin ( $90 \mathrm{mg} / \mathrm{kg}$ ) [27]. N $\omega$-Nitro-L-arginine methyl ester (L-NAME, Sigma Chemical) dissolved in a saline solution was i.p. administered (50 mg/kg) five days per week and beginning one day after the STZ injection. Control rats were injected with the same volume of saline solution. No insulin was administered. Animals were sacrificed between 9:30 and 11:00 a.m., along with age-matched control rats, at 7, 20 and 45 days after the STZ administration. Blood was collected, and the eyes were excised. The eyes were hemisected, and the retina was gently peeled away using fine forceps.

This study was carried out in strict accordance with the recommendations of the Mexican Institutes of Health Research (DOF. NOM-062-Z00-1999) and the National Institutes of Health Guide for the Care and Use of Laboratory Animals (NIH Publication No. 80-23, revised 1996). The protocol was approved by the Institutional Committee for the Care and Use of Laboratory Animals of the Institute of Cellular Physiology of the Autonomous National University of Mexico (CICUAL Comité Institucional para el Cuidado y Uso de los Animales de Laboratorio del Instituto de Fisiología Celular de la Universidad Nacional Autónoma de México) under Protocol Number RSS18-14; this was done in accordance with the Office of Laboratory Animal Welfare (OLAW), Assurance Number A5281-01.

All efforts were made to minimize animal suffering and to reduce the number of rats used.

\section{Diaphorase/NOS activity}

The presence of NADPH-d, a specific marker for NO-producing neurons [3-6], was detected by histochemistry performed on whole retinas and retina sections. The eyecups or the isolated retinas (whole mount preparation) were fixed for $45 \mathrm{~min}$ in 4\% paraformaldehyde in $100 \mathrm{mM}$ phosphate-buffered saline (PBS), pH 7.4. After being rinsed with PBS, retinas and $10 \mu \mathrm{m}$ sections were incubated at $37^{\circ} \mathrm{C}$ for $60 \mathrm{~min}$ in the following solution: $15 \mathrm{mM}$ malic acid; $1 \mathrm{mM} \mathrm{NADPH}$; $0.2 \mathrm{mM}$ nitro blue tetrazolium (NBT); $1 \%$ Triton $\mathrm{X}-100 ; 1 \mathrm{mM} \mathrm{MnCl}_{2}$; and $100 \mathrm{mM}$ Tris- $\mathrm{HCl}, \mathrm{pH} 8.0$ [28]. For the whole retinas, after the reaction, they were 


\section{Cellular Physiology Cell Physiol Biochem 2017;42:2353-2363 \begin{tabular}{l|l|l} 
and Biochemistry Published online: August 18, 2017 & $\begin{array}{l}\text { (c) } 2017 \text { The Author(s). Published by S. Karger AG, Basel } \\
\text { www.karger.com/cpb }\end{array}$
\end{tabular}}

mounted on a slide (ganglion cell layer on top), and the number of NADPH-d positive cells were analyzed over the entire retina.

\section{Immunohistochemistry}

The eyecups were fixed by immersion in 4\% paraformaldehyde in PBS, pH 7.4. After $1 \mathrm{~h}$, the tissue was rinsed in PBS and cryoprotected overnight at $4{ }^{\circ} \mathrm{C}$ in $30 \%$ sucrose-PBS. Retinal cryostat sections (10 $\mu \mathrm{m}$ ) were incubated for $45 \mathrm{~min}$ with PBS containing 5\% bovine serum albumin and 0.1\% Triton X-100. Sections were then incubated overnight at $4^{\circ} \mathrm{C}$ with either a mouse antibody against 3-nitrotyrosine (3-NT, diluted 1: 40, Santa Cruz Biotechnology), GFAP (glial fibrillary acidic protein, 1:1000, Chemicon), vimentin (1:500, Dako), or a rabbit antibody against iNOS (1:500, Abcam). This was followed by incubation for 2 h with a secondary Cy3-conjugated or Alexa Fluor 488 antibody (1:200, Zymed, or Thermo Fisher). For double immunofluorescence labeling, the two primary antibodies were applied simultaneously, followed by incubation with the corresponding secondary antibodies. At least four identically processed retina sections from 3-6 animals per group were analyzed. Negative immunohistochemical controls were conducted in parallel by omitting the primary antibody. Sections were examined using a Nikon microscope (Nikon Corp., Tokyo, Japan) and photographed with a Nikon DXM1200 digital camera (Nikon Corp., Tokyo, Japan). For double immunohistochemistry, images were overlapped using an image analysis program FIJI/ImageJ (National Institute of Health, Bethesda, MD).

\section{Nitric oxide levels}

Retinal nitric oxide levels were assessed by measuring total nitrate/nitrite concentrations (stable end-products of NO) in the supernatant of phosphate-buffered homogenates of rat retinas using the Griess method and a commercial assay kit (Cayman Chemical).

Cyclic GMP assay

Retinal cGMP content was determined by radioimmunoassay with a kit from Amersham following manufacturer's instructions.

\section{Western blotting}

Total protein solubilization was achieved by the homogenization of isolated retinas in a RIPA lysis buffer 1:4 (p/v) in RIPA-Tris buffer (2 mM EGTA; $316 \mathrm{mM} \mathrm{NaCl} ; 20 \mathrm{mM} \mathrm{Na} \mathrm{MoO}_{4} ; 50 \mathrm{mM} \mathrm{NaF} ; 20 \mathrm{mM}$ Tris$\mathrm{HCl} ; 100 \mathrm{mM} \mathrm{Na} \mathrm{VO}_{3} ; 100 \mathrm{mM}$ PMSF; $100 \mathrm{mM}$ EDTA; 0.1\% leupeptin and aprotinin; 0.2\% SDS and 2\% Triton X-100). Then, $50 \mu \mathrm{g}$ of protein was denatured in Laemmli's sample buffer [29], resolved via $10 \%$ SDSPAGE and subsequently transferred onto PVDF Immobilon membranes (Millipore Corp.). The molecular weight markers used were Precision Plus Protein Kaleidoscope standards from Bio-Rad. Nonspecific protein binding sites were blocked by incubating the membranes in $0.1 \%$ Tween 20, 1\% BSA, $20 \mathrm{mM}$ Tris- $\mathrm{HCl}$, and $136 \mathrm{mM} \mathrm{NaCl}, \mathrm{pH}$ 7.6, for $2 \mathrm{~h}$. Afterwards, they were incubated overnight at $4^{\circ} \mathrm{C}$ with mouse monoclonal antibodies against 3-nitrotyrosine (3-NT, 1:800, Santa Cruz Biotechnology). Proteins were visualized after applying a secondary HRP-conjugated antibody and a Chemiluminescent HRP Substrate (Immobilon Western Chemiluminescent HRP Substrate, Millipore Corp.); the intensity of the signals was revealed on Hyperfilm ECL (GE Healthcare Ltd.). Protein loading was normalized to actin using a mouse monoclonal primary antibody (1:500; Millipore-Corp.) and an anti-mouse horseradish peroxidase-conjugated secondary antibody (1:8,000 Healthcare Life Sci.). The blots were subjected to densitometric analyses, and the data were analyzed using Graph Pad Prism5 software (San Diego, CA, USA). The relative expression under the experimental conditions was obtained as $100 \%$ of the optical density of anormal retina on the same Western blot.

\section{Protein carbonylation}

Oxidized proteins were analyzed using a commercial kit (OxyBlot Protein Oxidation Detection Kit, Millipore) following the manufacturer's instructions. Carbonyl-hydrazine derivatized proteins were separated by polyacrylamide gel electrophoresis, followed by Western blotting using a primary rabbit antibody specific to hydrazone and a secondary anti-rabbit-HRP antibody that can be detected using a chemiluminescent HRP substrate as described above. 
Glucose and Protein Quantification

Glucose concentrations in the blood were determined with a blood glucometer (Accu-check glucose monitor, Roche).

Protein concentrations were determined by Lowry's method using a commercial assay kit (BioRad).

\section{Statistical Methods}

All data are presented as the mean \pm SEM of at least five separate experiments. The significance of the differences among the groups was assessed by one-way ANOVA followed by Tukey's analysis.

\section{Results}

In accordance with previous reports, rats were considered diabetic if they had blood glucose levels over $250 \mathrm{mg} / \mathrm{ml}$

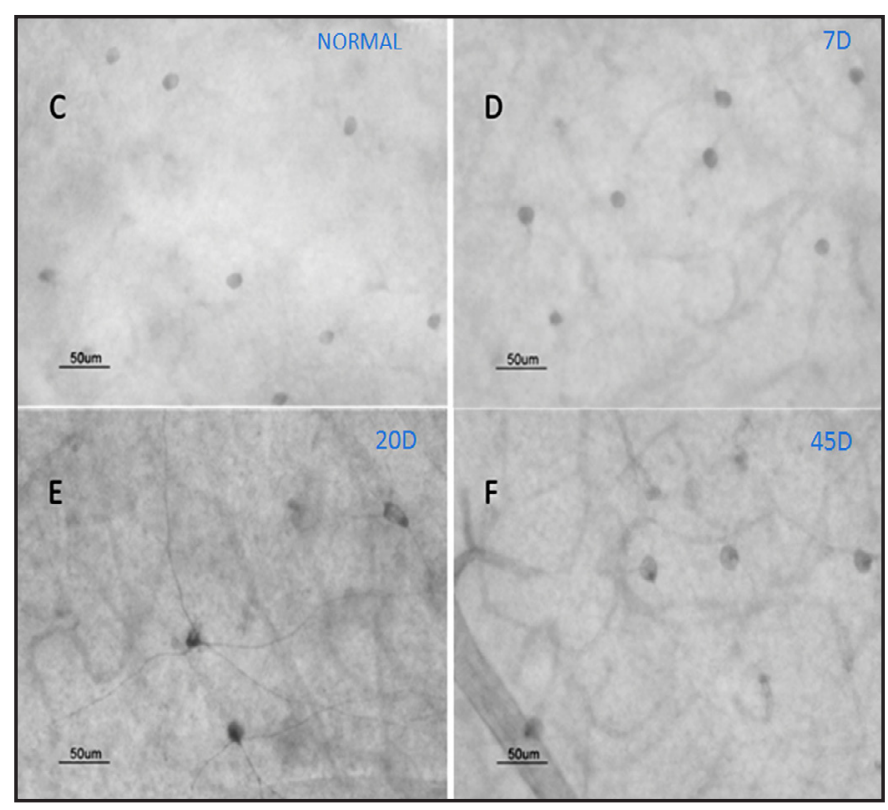

Fig. 1. Histochemistry for NADPH-d. Whole-mounted retinas from (A) normal rats and rats at (B) 7 days, (C) 20 days and (D) 45 days after diabetes induction. Increased NADPH-d staining intensity was observed at 20 and 45 days after the onset of diabetes, albeit the number of NADPH-d positive cells did not change. during the treatment and at the time of sacrifice.

In the whole mount normal retina, NADPH-d histochemistry revealed slightly stained ganglion cells with infrequently well-visualized dendrites, as has been previously reported $[8,9]$; faint labeling was also found in blood vessels. An increase in NADPH-d staining was found at 20 and 45 days after diabetes onset (Fig. 1); however, the number of NADPH-d positive cells was similar in normal and diabetic animals (Fig. 2), suggesting an increase in enzyme activity in the same type of cells.

Histochemistry for NADPH-d was also performed on retinal sections. As shown in Figure 3, almost imperceptible labeling was found in the

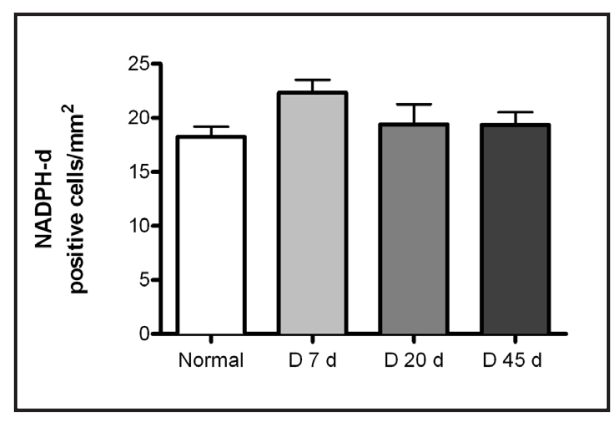

Fig. 2. Number of NADPH-diaphorasepositive cells in whole-mounted retinas from normal and diabetic rats. Data are the mean \pm SEM from at least three retinas per group.

Fig. 3. Diabetes increases NADPH-d activity in the retina. Representative histochemistry images showing increased activity of NADPH-d within the ganglion cell layer (GCL), inner plexiform layer (IPL), outer plexiform layer (OPL) and

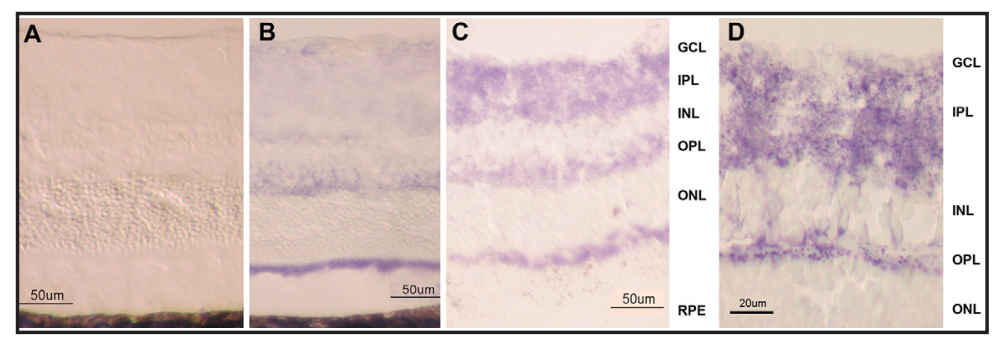
Müller cell projections in the diabetic rat retinas compared with the normal rat retinas. Inner nuclear layer (INL) and outer nuclear layer (ONL) showing little or no labeling. No differences were observed at 7 days after the onset of diabetes. (A) Normal, (B) 20 days after the onset of diabetes, (C) 45 days after the onset of diabetes, D) 45 days after the onset of diabetes at higher magnification. Bars represent $50 \mu \mathrm{m}(\mathrm{A}, \mathrm{B}, \mathrm{C})$ and $20 \mu \mathrm{m}(\mathrm{D})$. 


\section{Cellular Physiology Cell Physiol Biochem 2017;42:2353-2363 \begin{tabular}{l|l} 
DOI: 10.1159/000480007 & O 2017 The Author(s). Published by S. Karger AG, Basel \\
www.karger.com/cpb
\end{tabular}

normal rat retinas; no differences were observed at 7 days after the onset of diabetes (not shown). At 20 and 45 days after streptozotocin treatment, intense staining was observed in the diabetic rat retinas compared with that in the normal animals, and this intense staining was located particularly in the ganglion cell layer (GCL), inner plexiform layer (IPL) and outer plexiform layer (OPL) (in synaptic layers, the labeling was observed as dots) and in the outer segments of photoreceptor cells. Labeling was also detected in the inner nuclear layer (INL) and scanty filaments extending across the thickness of the retina, which might represent prolongations of neurons and glial Müller cells.

Then, we determined NO levels in normal and diabetic rat retinas. Ex vivo retinas from normal rats showed NO levels of $4.4 \pm 0.4 \mu \mathrm{M} / \mathrm{mg}$ protein (Fig. 4). Remarkably, as shown in Figure 4, NO levels significantly increased in diabetic retinas as a function of time.

To identify the NOS isoform related to the increase in NO, we performed immunohistochemistry for

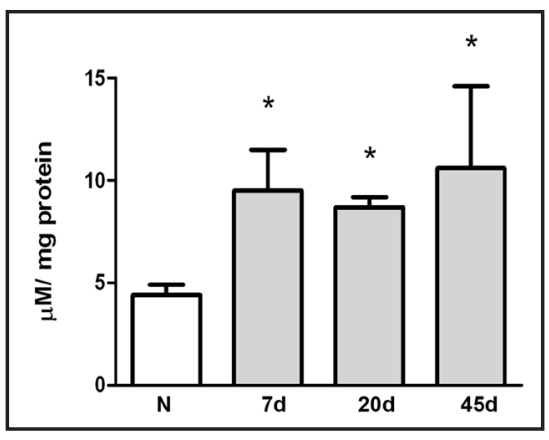

Fig. 4. Nitric oxide levels in normal and diabetic rat retinas. Nitric oxide levels $(\mu \mathrm{M} / \mathrm{mg}$ protein) increased significantly in diabetic rat retinas at 7 days (7d), 20 days (20d) and 45 days (45d) after streptozotocin administration compared to those in normal $(\mathrm{N})$ rat retinas. Values are the mean \pm SEM from six different animals per group. ${ }^{*} \mathrm{p} \leq 0.05$ with respect to the normal rats. iNOS. Normal retinas did not show immunoreactivity for iNOS, but strong immunoreactivity was found in the diabetic retinas (Fig. 5). iNOS immunoreactivity increased with the time of hyperglycemia suffering. Labeling for iNOS was observed in the ganglion and inner nuclear layers, photoreceptor cells, and intense points at the inner plexiform layer. Double immunolabeling revealed slight iNOS expression in Müller cell processes in the diabetic rat retinas (Fig. 6).

We were also interested in determining whether the increase in NO was associated with the guanylate kinase pathway; therefore, we measured cGMP in the retinas from normal and diabetic rats. Ex vivo retinas from normal rats contained $12 \pm 1.6 \mathrm{pmol} / \mathrm{mg}$ protein of cGMP. Unexpectedly, as shown in Figure 7, cGMP levels in diabetic rat retinas were not significantly different from those of normal rat retinas.

Furthermore, positive immunolabeling of nitrotyrosine, a putative marker of peroxynitrite, was observed at 20 and 45 days after the onset of diabetes; prominent staining was found in retinal vessels and photoreceptor layers. Diffuse labeling was also observed in the ganglion cell layer and inner and outer plexiform layers of diabetic rat retinas (Fig. 8). Double immunolabeling showed faint colocalization of nitrotyrosine with some processes of the Müller glial cells (Fig. 9).

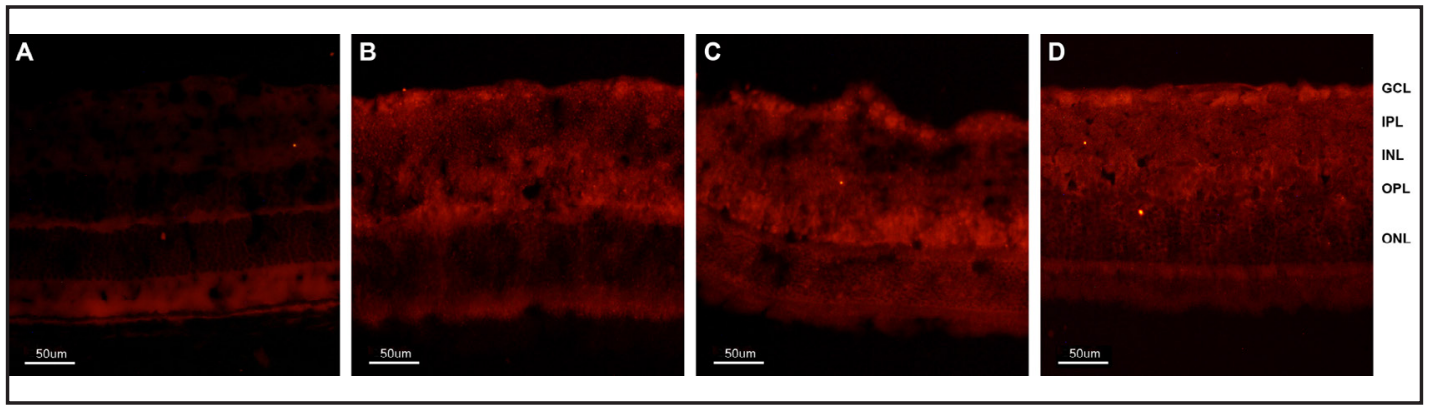

Fig. 5. Diabetes increases inducible nitric oxide synthase in the rat retina. Retinal sections $(10 \mu \mathrm{m})$ from $(\mathrm{A})$ normal and diabetic rat retinas from (B) 7 days, (C) 20 days and (D) 45 days after diabetes induction. Positive immunoreactivity of iNOS was observed within the ganglion cell layer (GCL) and inner plexiform and nuclear layers (IPL and INL) and in photoreceptor cells (ONL); weak labeling was observed at the Müller cell endfeet and processes. Bars represent $50 \mu \mathrm{m}$. 


\section{Cellular Physiology

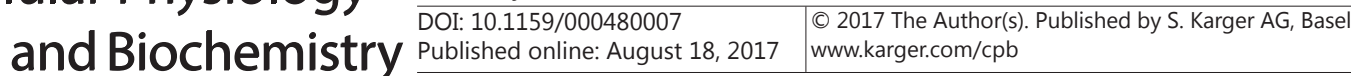

Fig. 6. Müller cell processes express small amounts of iNOS in diabetic rat retinas. (A) Double immunofluorescence labeling of iNOS in red and (B) vimentin in green. (C) Overlapped images showed slight expression of iNOS in Müller cell processes in the
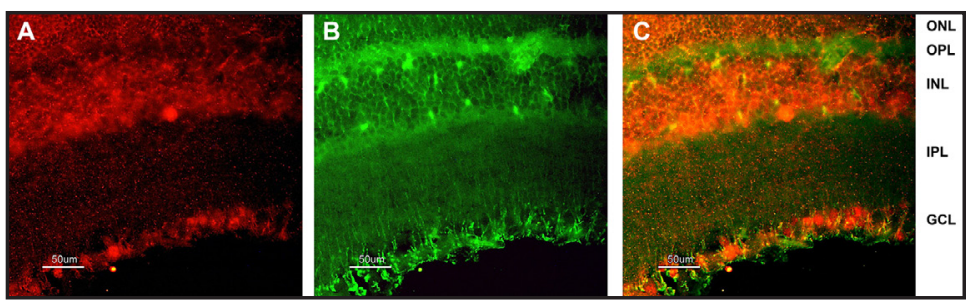
retinas of 20-day diabetic rats. Outer nuclear layer (ONL), outer plexiform layer (OPL), inner plexiform layer (IPL), inner nuclear layer (INL) and ganglion cells layer (GCL). Bars represent $50 \mu \mathrm{m}$.

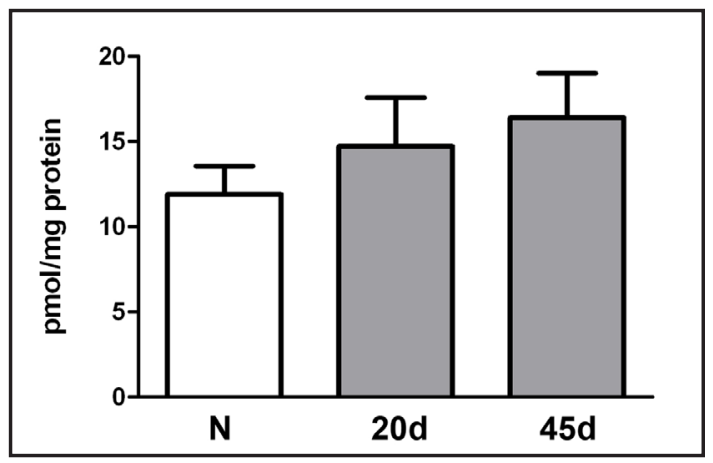

Fig. 7. cGMP content in normal and 20- and 45-day diabetic rat retinas. Values are the mean \pm SEM from six different animals per group.

In addition, glial activation displayed by enhanced GFAP immunoreactivity in the retina was found as early as 7 days after the onset of diabetes (Fig. 10).

Likewise, several nitrotyrosine immunoreactive protein bands from normal and diabetic rat retinas were found. As shown in Figure 11, the Western blot analysis revealed that the level of nitrated proteins progressively increased in accordance with the time of diabetes induction. Furthermore, we also observed an increase in the oxidized proteins in the retinas from diabetic rats early after diabetes induction (Fig. 12). As shown in Figure 12, L-NAME administration significantly reduced the levels of oxidized proteins in diabetic rat retinas. Despite this, treatment with L-NAME did not change blood glucose levels in the diabetic rats (data not shown).
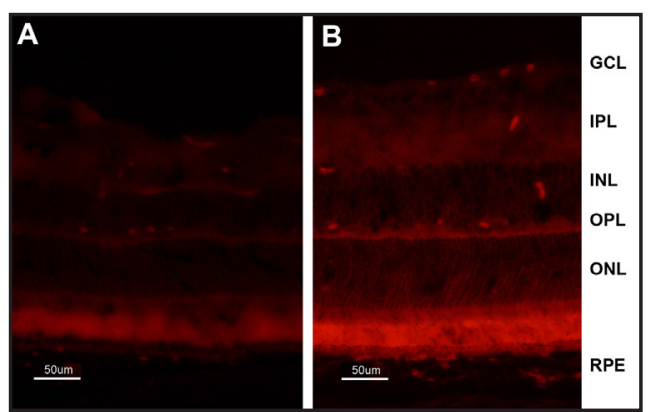

Fig. 8. Diabetes increases nitrotyrosine formation in the rat retina. Retinal sections (10 $\mu \mathrm{m}$ ) from (A) normal and (B) 20-day diabetic rats. Positive immunoreactivity of nitrotyrosine was observed within retinal vessels and photoreceptor cells, and diffuse labeling was observed at the ganglion cell layer (GCL) and inner and outer plexiform layers (IPL, OPL). Bars represent $50 \mu \mathrm{m}$.
Fig. 9. Increased 3-nitrotyrosine expression in diabetic rat retinas. Double immunofluorescence labeling of (A) 3-nitrotyrosine in green and

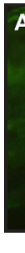

(B) vimentin in red. (C)

Overlapped images showed faint colocalization of nitrotyrosine at the Müller cell processes endfeet. Outer nuclear layer (ONL), outer plexiform layer (OPL), inner plexiform layer (IPL), inner nuclear layer (INL) and ganglion cells layer (GCL). Bars represent $50 \mu \mathrm{m}$.

\section{KARGER}


Fig. 10. The expression of glial fibrillary acidic protein is increased in diabetic rat retinas. Representative microphotographs of GFAP immunoreactivity in $10 \mu \mathrm{m}$ retinal sections. (A) Normal, (B)
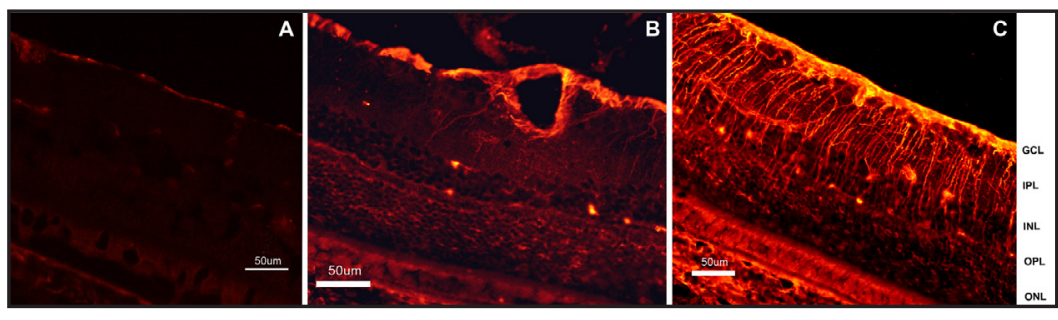
7-day diabetic and (C) 20-day diabetic rat retinas. Intense labeling is observed in the astrocytes and Müller cell endfeet. Pictures were taken at the same exposure time; overexposure (yellow signal) indicates the increased expression of GFAP. Ganglion cells layer (GCL), inner plexiform layer (IPL), inner nuclear layer (INL), outer plexiform layer (OPL), outer nuclear layer (ONL). Bars represent $50 \mu \mathrm{m}$.

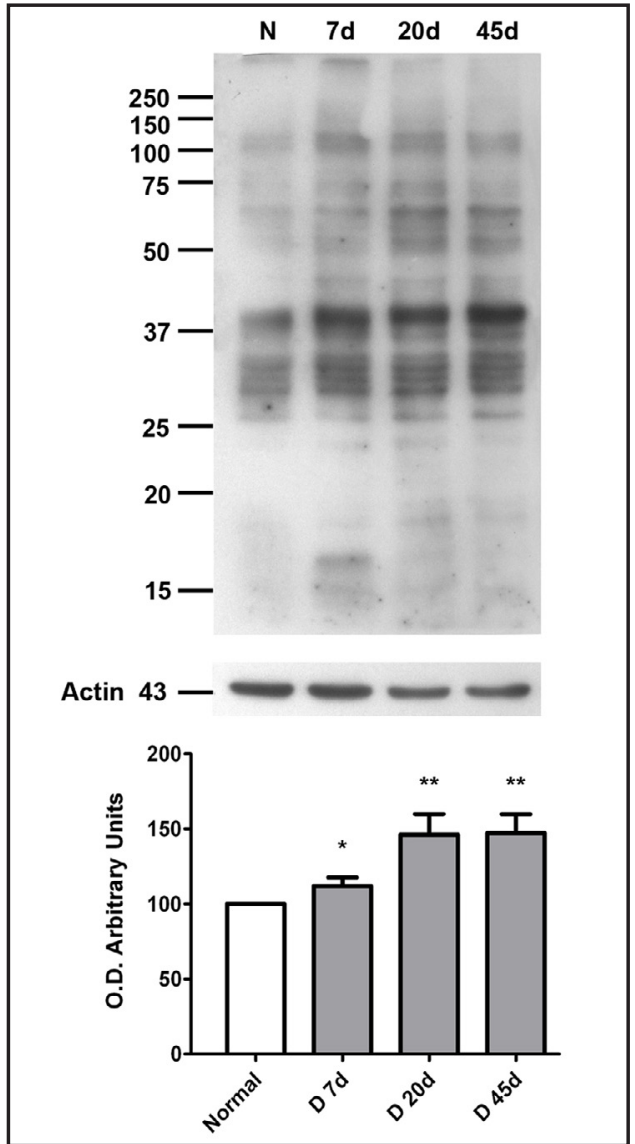

Fig. 11. Diabetes increases nitrated protein levels in the rat retina. Upper part, representative Western blot of nitrated proteins from normal $(\mathrm{N})$ and diabetic rat retinas at 7 days $(7 \mathrm{~d})$, 20 days (20d) and 45 days (45d) after streptozotocin administration. Lower part, graphic representation of the relative optical density for each lane ( $30 \mu \mathrm{g}$ of protein was loaded) is plotted. Values are the mean \pm SEM of at least three different animals per group, performed in triplicate. ${ }^{*} \mathrm{p} \leq 0.005$ with respect to the normal rats.

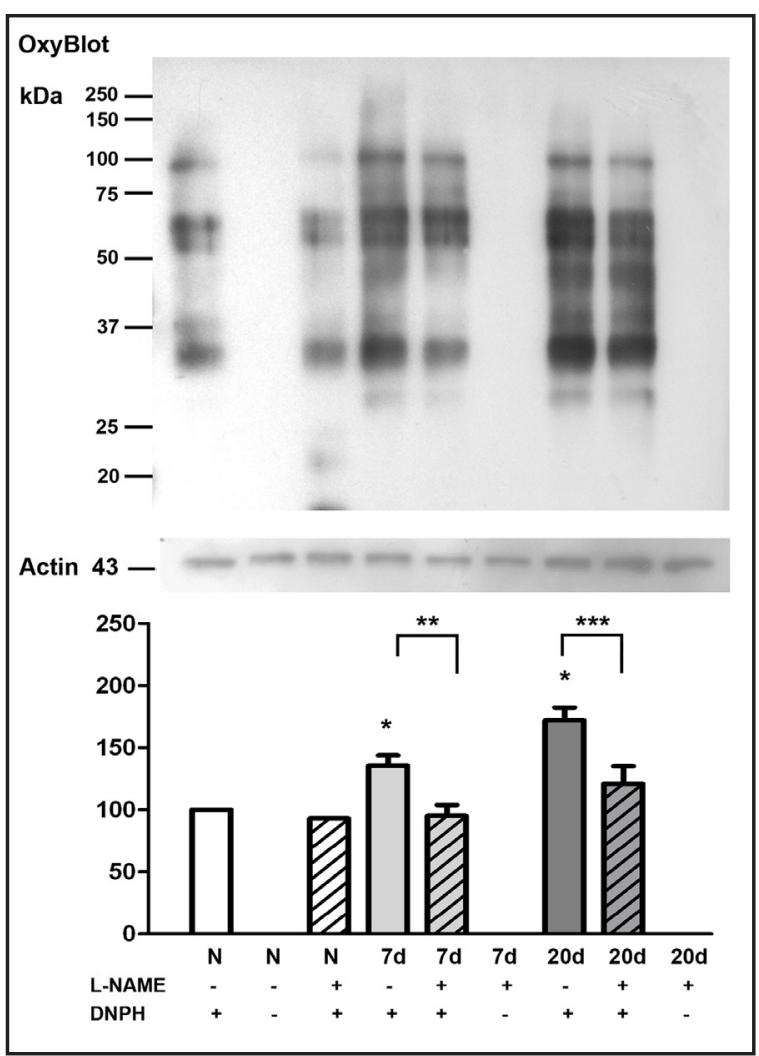

Fig. 12. Increased levels of carbonylated proteins in normal and diabetic rat retinas are ablated by L-NAME treatment. Levels of oxidized proteins in normal (N) and diabetic rat retinas at 7 days $(7 \mathrm{~d})$, and 20 days $(20 \mathrm{~d})$ after streptozotocin administration and treated with $(+)$ or without (-) L-NAME. L-NAME $(50 \mathrm{mg} / \mathrm{kg})$ was administered as described in the Methods section. The upper panel is a representative Western blot. The lower panel shows the relative values of oxidized proteins. The negative control for each sample was not derivatized with dinitrophenylhydrazine (DNPH). Data are the mean \pm SEM of four different experiments. ${ }^{*} \mathrm{p} \leq 0.05$ with respect to the normal sample, ${ }^{* *} \mathrm{p} \leq 0.01$ and ${ }^{* * *} \mathrm{p} \leq 0.03$ with respect to the same day without L-NAME treatment. 


\section{Discussion}

Nitric oxide is an important cellular signaling molecule involved in many physiological and pathological processes $[3,4,18,19]$. NO mediates its effects through the production of cGMP from the enzyme NO-sensitive sGC $[12,13]$. In the retina, the NO-cGMP pathway is involved in the modulation of visual information processing. However, NO may also modify cysteine and tyrosine residues, thereby modulating the function of a variety of target proteins [14-17].

A variety of evidential factors indicate that diabetic retinopathy is associated with nitrosative stress [23-25]. However, nitrosative stress has been demonstrated to appear after at least six weeks of diabetes in experimental animals [30,31], while retinal cell death [32] and visual deficits occur as early as two weeks after the onset of diabetes in animal models [33-35]. Therefore, in the present study, we analyzed whether the increase in NO occurred during the early stages of hyperglycemia and whether this led to changes in the NO-cGMP signaling pathway and in nitrosative stress in a streptozotocin-induced rat model of diabetes.

In normal whole mount retinas, slight staining for NADPH-d was mainly found in ganglion cells. These results agree with immunohistochemistry studies in which nNOS expression was detected predominantly in the inner retina between the inner nuclear and ganglion cell layers $[8,9]$. Additionally, NO was observed in many somata in the inner nuclear layer and buttons in the inner plexiform layer in the retina under steady light [36]. However, it has been reported that NADPH-d activity, but not nNOS immunoreactivity, is present in photoreceptor ellipsoids [7], whereas Neufeld et al. demonstrated nNOS immunoreactivity in photoreceptors [8]; this discrepancy continues to date [37].

In the retinas of diabetic animals, as early as 20 days after diabetes induction, we found a significant increase in NADPH-d staining. This increase, observed in neurons and retinal vessels, appears to be due to enhanced activity and not to an increase in the number of positive ganglion cells (Fig. 2). These results disagree with those in which the number of NADPH-d positive neurons decreased after one week of diabetes and remained decreased in long-term diabetic rats [38]. However, they agree with results in which there was an increase in retinal nNOS immunoreactivity [39]. In fact, NADPH-d histochemistry of retinal sections revealed staining at the ganglion cell layer, as well as intense, compact punctate labeling in the inner and outer plexiform layers, suggesting the presence of this enzyme at the synaptic terminals, as reported by other authors [39]. Interestingly, NADPH-d staining was also observed to increase in Müller cells but decrease in amacrine cells [39].

Likewise, upregulation of iNOS was found in the retinas from long-term streptozotocininduced diabetes, as well as the retinas from spontaneous diabetic rats [23, 25]. It is also worth noting that a NOS inhibitor, aminoguanidine, slowed the development of diabetic retinopathy in diabetic animals [25]. In agreement with these results, we found iNOS immunoreactivity increased in the retina early after diabetes induction.

According to the increase in NADPH-d activity and iNOS immunoreactivity, NO levels were found to increase by $100 \%$ in the retina as early as 7 days after diabetes induction, compared to those in normal rats. This increase in NO production agreed with the remarkable decrease in the retinal content of the NO precursor, arginine, observed at 20 days after streptozotocin induction of diabetes [27]. Notably, the increase in NO levels did not correlate with changes in cGMP levels. We did not find significant differences in cGMP levels between normal and diabetic rat retinas. Similarly, overproduction of NO did not activate sGC in the retina at 6 and 12 weeks after diabetes induction [32]. Since we determined cGMP levels in the whole retina, our results might suggest that changes in cGMP occurred in different cell populations, which may have differed in their synthesis and degradation activities. Although several groups have concluded that the NO-cGMP pathway modulates the neural circuitry in the inner retina [40-42], the most pronounced effect of dark adaptation in the rat retina is an enhancement of NADPH-d activity in Müller cells. Moreover, Müller cells were reported to be immunonegative for sGC [22], which may explain our results. On the other hand, the 
increase in $\mathrm{NO}$ in the retinas of diabetic rats may have led to nitrosative stress. In fact, the role of NO in diabetic retinopathy has been suggested by findings that iNOS increases in retinas after long-term streptozotocin-induced diabetes $[23,25]$ and in human patients [20, $24,43]$, as well as in Müller cells in culture [44]. Neurons and glia were also found to stain positive for nitrotyrosine in diabetic rats after four weeks of experimental diabetes [20, $21,25]$. Moreover, NO has been shown to be proangiogenic in the retina and choroids, and angiogenesis has been found to be present in diabetic retinopathy $[45,46]$.

Furthermore, the increase in NO levels may produce nitrated proteins [47]. In this respect, we found increased levels of nitrated proteins, an effect that was related to the time of diabetes induction. In addition, we detected positive immunoreactivity for nitrotyrosine in retinal vessels as well as in photoreceptors, nuclear layers and some processes of the Müller cells, indicating the occurrence of nitrosative stress at very early stages of diabetes. Indeed, we observed the expression of GFAP in Müller cell end feet at 7 days after the onset of diabetes, indicative of stress in these cells. Because Müller cells participate in many retinal functions [48], these abnormalities may have enhanced or initiated alterations in neurons and vessels. However, our results disagree with previous studies in which no differences in GFAP expression were observed between normal and four-week diabetic rat retinas [49].

In addition, we observed an increase in oxidized proteins at the onset of diabetes induction, which were remarkably reduced to normal levels after treatment with the NOS inhibitor L-NAME. Nevertheless, since L-NAME inhibits both nNOS and iNOS, we cannot rule out the participation of nNOS. In addition to the nitration of tyrosine residues, nitrating species have been reported to cause nitrosation of histidine and oxidation of cysteine and methionine residues [50]. What is more, a number of studies have indicated that nitration of proteins, at least in cell model systems, could significantly alter protein function and protein turnover, influence immune responses, and be involved in signal transduction processes [47]. Our results suggest that the high NO levels produced under hyperglycemic conditions induced protein alterations (nitration/oxidation) that in turn led to cellular stress, which may have triggered retinopathy. Whether high glucose concentrations directly induce NOS expression or increases in its activity remains to be elucidated. In addition, reports have proposed that hyperglycemia results in retinal neural cell death via the neuroprotective effect of insulinmediated Akt signaling $[51,52]$. Similarly, the participation of other signaling pathways and the occurrence of hyperglycemic cell protecting factors have been reported [53-56]. Further studies at the cellular and molecular level are necessary to elucidate the role of insulin in the modulation of the NO-cGMP signaling pathway in the retina and its relation to retinopathy.

\section{Acknowledgements}

This study was partially supported by PAPIIT/ UNAM grants IN202813 \& IG200216. The authors acknowledge Ms. S. Baker and Ms. S. Zamora for carrying out some of the experiments, and Mr. S. Albert-Garay for helping with the double immunohistochemistry figures preparation.

\section{Disclosure Statement}

The authors report no conflicts of interest.

\section{References}

Sessa WC: The nitric oxide synthase family of proteins. J Vasc Res 1994;31:131-143.

Forstermann U, Sessa WC: Nitric oxide synthases: Regulation and function. Eur Heart J 2012;33:829-837.

Bredt DS, Snyder SH: Nitric oxide, a novel neuronal messenger. Neuron 1992;8:3-11.

Ignarro LJ: Nitric oxide. A novel signal transduction mechanism for transcellular communication.

Hypertension 1990;16:477-483.

-5 Bredt DS, Hwang PM, Snyder SH: Localization of nitric oxide synthase indicating a neural role for nitric oxide. Nature 1990;347:768-770. 


\section{Cellular Physiology Cell Physiol Biochem 2017;42:2353-2363 \begin{tabular}{l|l} 
and Biochemistry Published online: August 18, 2017 & $\begin{array}{l}\text { (c) } 2017 \text { The Author(s). Published by S. Karger AG, Basel } \\
\text { www.karger.com/cpb }\end{array}$
\end{tabular}}

6 Bredt DS, Glatt CE, Hwang PM, Fotuhi M, Dawson TM, Snyder SH: Nitric oxide synthase protein and mRNA are discretely localized in neuronal populations of the mammalian CNS together with NADPH diaphorase. Neuron 1991;7:615-624.

7 Yamamoto R, Bredt DS, Snyder SH, Stone RA: The localization of nitric oxide synthase in the rat eye and related cranial ganglia. Neuroscience 1993;54:189-200.

8 Neufeld AH, Shareef S, Pena J: Cellular localization of neuronal nitric oxide synthase (nos-1) in the human and rat retina. J Comp Neurol 2000;416:269-275.

-9 Kim IB, Oh SJ, Chun MH: Neuronal nitric oxide synthase immunoreactive neurons in the mammalian retina. Microsc Res Tech 2000;50:112-123.

10 Palanza L, Jhaveri S, Donati S, Nuzzi R, Vercelli A: Quantitative spatial analysis of the distribution of nadphdiaphorase-positive neurons in the developing and mature rat retina. Brain Res Bull 2005;65:349-360.

11 Sitaramayya A: Soluble guanylate cyclases in the retina. Mol Cell Biochem 2002;230:177-186.

12 Blom J, Giove T, Deshpande M, Eldred WD: Characterization of nitric oxide signaling pathways in the mouse retina. J Comp Neurol 2012;520:4204-4217.

13 Lucas KA, Pitari GM, Kazerounian S, Ruiz-Stewart I, Park J, Schulz S, Chepenik KP, Waldman SA: Guanylyl cyclases and signaling by cyclic GMP. Pharmacol Rev 2000;52:375-414.

14 Marozkina NV, Gaston B: S-nitrosylation signaling regulates cellular protein interactions. Biochim Biophys Acta 2012;1820:722-729.

15 Smith BC, Marletta MA: Mechanisms of s-nitrosothiol formation and selectivity in nitric oxide signaling. Curr Opin Chem Biol 2012;16:498-506.

16 Hess DT, Matsumoto A, Kim SO, Marshall HE, Stamler JS: Protein s-nitrosylation: Purview and parameters. Nat Rev Mol Cell Biol 2005;6:150-166.

17 Wei W, Li B, Hanes MA, Kakar S, Chen X, Liu L: S-nitrosylation from gsnor deficiency impairs DNA repair and promotes hepatocarcinogenesis. Sci Transl Med 2010;2:19ra13.

18 Pacher P, Beckman JS, Liaudet L: Nitric oxide and peroxynitrite in health and disease. Physiol Rev 2007;87:315-424.

19 Szabo C, Ischiropoulos H, Radi R: Peroxynitrite: Biochemistry, pathophysiology and development of therapeutics. Nat Rev Drug Discov 2007;6:662-680.

-20 Ali TK, Matragoon S, Pillai BA, Liou GI, El-Remessy AB: Peroxynitrite mediates retinal neurodegeneration by inhibiting nerve growth factor survival signaling in experimental and human diabetes. Diabetes 2008;57:889-898.

21 Stavniichuk R, Shevalye H, Lupachyk S, Obrosov A, Groves JT, Obrosova IG, Yorek MA: Peroxynitrite and protein nitration in the pathogenesis of diabetic peripheral neuropathy. Diabetes Metab Res Rev 2014;30:669-678.

22 Ding JD, Weinberg RJ: Distribution of soluble guanylyl cyclase in rat retina. J Comp Neurol 2007;500:734745.

23 Carmo A, Cunha-Vaz JG, Carvalho AP, Lopes MC: Nitric oxide synthase activity in retinas from non-insulindependent diabetic goto-kakizaki rats: Correlation with blood-retinal barrier permeability. Nitric Oxide 2000;4:590-596.

24 Abu El-Asrar AM, Desmet S, Meersschaert A, Dralands L, Missotten L, Geboes K: Expression of the inducible isoform of nitric oxide synthase in the retinas of human subjects with diabetes mellitus. Am J Ophthalmol 2001;132:551-556.

25 Du Y, Smith MA, Miller CM, Kern TS: Diabetes-induced nitrative stress in the retina, and correction by aminoguanidine. J Neurochem 2002;80:771-779.

26 Salceda R, Hernandez-Espinosa C, Sanchez-Chavez G: L-arginine uptake in normal and diabetic rat retina and retinal pigment epithelium. Neurochem Res 2008;33:1541-1545.

27 Vilchis C, Salceda R: Effect of diabetes on levels and uptake of putative amino acid neurotransmitters in rat retina and retinal pigment epithelium. Neurochem Res 1996;21:1167-1171.

-28 Sagar SM: NADPH diaphorase histochemistry in the rabbit retina. Brain Res 1986;373:153-158.

29 Laemmli UK: Cleavage of structural proteins during the assembly of the head of bacteriophage t4. Nature 1970;227:680-685.

30 Li Q Zemel E, Miller B, Perlman I: NADPH diaphorase activity in the rat retina during the early stages of experimental diabetes. Graefes Arch Clin Exp Ophthalmol 2003;241:747-756.

-31 Schaefer S, Kajimura M, Tsuyama S, Uchida K, Sato E, Inoue M, Suematsu M, Watanabe K: Aberrant utilization of nitric oxide and regulation of soluble guanylate cyclase in rat diabetic retinopathy. Antioxid Redox Signal 2003;5:457-465. 


\section{Cellular Physiology Cell Physiol Biochem 2017;42:2353-2363 \begin{tabular}{l|l|l} 
and Biochemistry Published online: August 18, 2017 & $\begin{array}{l}\text { (c) } 2017 \text { The Author(s). Published by S. Karger AG, Basel } \\
\text { www.karger.com/cpb }\end{array}$
\end{tabular}}

32 Barber AJ: A new view of diabetic retinopathy: A neurodegenerative disease of the eye. Prog Neuropsychopharmacol Biol Psychiatry 2003;27:283-290.

-33 Li Q, Zemel E, Miller B, Perlman I: Early retinal damage in experimental diabetes: Electroretinographical and morphological observations. Exp Eye Res 2002;74:615-625.

-34 Shinoda K, Rejdak R, Schuettauf F, Blatsios G, Volker M, Tanimoto N, Olcay T, Gekeler F, Lehaci C, Naskar R, Zagorski Z, Zrenner E: Early electroretinographic features of streptozotocin-induced diabetic retinopathy. Clin Experiment Ophthalmol 2007;35:847-854.

-35 Aung MH, Kim MK, Olson DE, Thule PM, Pardue MT: Early visual deficits in streptozotocin-induced diabetic long evans rats. Invest Ophthalmol Vis Sci 2013;54:1370-1377.

-36 Koistinaho J, Swanson RA, de Vente J, Sagar SM: NADPH-diaphorase (nitric oxide synthase)-reactive amacrine cells of rabbit retina: Putative target cells and stimulation by light. Neuroscience 1993;57:587597.

-37 Vielma AH, Retamal MA, Schmachtenberg O: Nitric oxide signaling in the retina: What have we learned in two decades? Brain Res 2012;1430:112-125.

-38 Roufail E, Soulis T, Boel E, Cooper ME, Rees S: Depletion of nitric oxide synthase-containing neurons in the diabetic retina: Reversal by aminoguanidine. Diabetologia 1998;41:1419-1425.

39 Giove TJ, Deshpande MM, Gagen CS, Eldred WD: Increased neuronal nitric oxide synthase activity in retinal neurons in early diabetic retinopathy. Mol Vis 2009;15:2249-2258.

40 Zemel E, Eyal O, Lei B, Perlman I: NADPH diaphorase activity in mammalian retinas is modulated by the state of visual adaptation. Vis Neurosci 1996;13:863-871.

41 Hoshi H, Sato M, Oguri M, Ohtsuka T: In vivo nitric oxide concentration in the vitreous of rat eye. Neurosci Lett 2003;347:187-190.

42 Eldred WD, Blute TA: Imaging of nitric oxide in the retina. Vision Res 2005;45:3469-3486.

43 Abu-El-Asrar AM, Dralands L, Missotten L, Al-Jadaan IA, Geboes K: Expression of apoptosis markers in the retinas of human subjects with diabetes. Invest Ophthalmol Vis Sci 2004;45:2760-2766.

44 Du Y, Sarthy VP, Kern TS: Interaction between NO and COX pathways in retinal cells exposed to elevated glucose and retina of diabetic rats. Am J Physiol Regul Integr Comp Physiol 2004;287:R735-741.

-45 Ando A, Yang A, Mori K, Yamada H, Yamada E, Takahashi K, Saikia J, Kim M, Melia M, Fishman M, Huang P, Campochiaro PA: Nitric oxide is proangiogenic in the retina and choroid. J Cell Physiol 2002;191:116-124.

46 Wilkinson-Berka JL: Vasoactive factors and diabetic retinopathy: Vascular endothelial growth factor, cycoloxygenase-2 and nitric oxide. Curr Pharm Des 2004;10:3331-3348.

47 Ischiropoulos H: Biological selectivity and functional aspects of protein tyrosine nitration. Biochem Biophys Res Commun 2003;305:776-783.

-48 Bringmann A, Pannicke T, Grosche J, Francke M, Wiedemann P, Skatchkov SN, Osborne NN, Reichenbach A: Müller cells in the healthy and diseased retina. Progress in Retinal and Eye Research 2006;25:397-424.

49 Rungger-Brändle E, Dosso AA, Leuenberger PM: Glial reactivity, an early feature of diabetic retinopathy. Invest Ophthalmol Vis Sci 2000;41:1971-1980.

50 Haqqani AS, Kelly JF, Birnboim HC: Selective nitration of histone tyrosine residues in vivo in mutatect tumors. J Biol Chem 2002;277:3614-3621.

-51 Nakamura M, Barber AJ, Antonetti DA, LaNoue KF, Robinson KA, Buse MG, Gardner TW: Excessive hexosamines block the neuroprotective effect of insulin and induce apoptosis in retinal neurons. J Biol Chem 2001;276:43748-43755.

-52 Kuser-Abali G, Ozcan F, Ugurlu A, Uysal A, Fuss SH, Bugra-Bilge K: Sik2 is involved in the negative modulation of insulin-dependent muller cell survival and implicated in hyperglycemia-induced cell death. Invest Ophthalmol Vis Sci 2013;54:3526-3537.

53 Liu B, Li CP, Wang WQ Song SG, Liu XM: Lignans extracted from eucommia ulmoides oliv. Protects against ages-induced retinal endothelial cell injury. Cell Physiol Biochem 2016;39:2044-2054.

54 Zhou RM, Shen Y, Yao J, Yang H, Shan K, Li XM, Jiang Q, Yan B: Nmnat 1: A security guard of retinal ganglion cells (RGCS) in response to high glucose stress. Cell Physiol Biochem 2016;38:2207-2218.

55 Veluthakal R, Kumar B, Mohammad G, Kowluru A, Kowluru RA: Tiam1-rac1 axis promotes activation of p38 map kinase in the development of diabetic retinopathy: Evidence for a requisite role for protein palmitoylation. Cell Physiol Biochem 2015;36:208-220.

56 Li YJ, Jiang Q, Cao GF, Yao J, Yan B: Repertoires of autophagy in the pathogenesis of ocular diseases. Cell Physiol Biochem 2015;35:1663-1676. 